\title{
PERCEPÇÃO DAS PUÉRPERAS SOBRE A ASSISTÊNCIA HUMANIZADA DE ENFERMAGEM NO CICLO GRAVÍDICO-PUERPERAL: REVISÃO DE LITERATURA
}

\section{PERCEPTION OF PUERPERAL WOMEN ABOUT HUMANIZED NURSING CARE IN THE PREGNANCY-PUERPERAL CYCLE: LITERATURE REVIEW}

\section{Lílian Brena Costa de Souza ${ }^{1}$ José Erivelton de Souza Maciel Ferreira ${ }^{2} *$ Lídia Rocha de Oliveira $^{3} *$ Anne Fayma Lopes Chaves ${ }^{4}$ Alana Santos Monte ${ }^{5}$}

\section{RESUMO}

Objetivo: Analisar na literatura a percepção da puérpera sobre a assistência humanizada de enfermagem prestada durante o ciclo gravídico-puerperal. Métodos: Trata-se de uma revisão integrativa realizada com base na seguinte pergunta norteadora: "Qual a percepção das puérperas sobre a assistência humanizada de enfermagem prestada no ciclo gravídico-puerperal?". A busca dos artigos foi realizada nas bases de dados BDENF, LILACS e SciELO, a partir dos descritores controlados "Humanização da Assistência", "Enfermagem Obstétrica" e "Cuidados de Enfermagem". Resultados: A amostra totalizou 12 artigos, os quais apontaram tanto aspectos positivos quanto negativos da assistência humanizada de enfermagem. Sobre os aspectos positivos, foram evidenciados: no pré-natal, a criação do vínculo entre profissional-paciente e as ações educativas em saúde; no âmbito do parto foi enfatizado a empatia profissional e as boas práticas preconizadas pela Rede Cegonha e Organização Mundial da Saúde; no contexto do puerpério, revelou-se a preocupação dos enfermeiros com o conforto e bem-estar da mulher. Sobre os aspectos negativos, pode-se destacar a execução de procedimentos sem autorização prévia da puérpera, relatos de coerção e violação ao direito de acompanhante, e no puerpério a ausência de ações educativas de saúde direcionadas para a prevenção de intercorrências puerperais e/ou mamárias. Conclusão: O enfermeiro deve estar pautado na humanização, exercendo uma postura idealizadora de caráter cuidador, de modo que possa desempenhar a sua prática com vista à efetivação dos direitos sexuais e reprodutivos das mulheres antes e depois do ciclo gravídico-puerperal.

Palavras-chave: Enfermagem; Humanização da Assistência; Enfermagem Obstétrica; Cuidados de Enfermagem.

\begin{abstract}
Objective: To analyze in the literature the perception of postpartum women about humanized nursing care provided during the pregnancy-puerperal cycle. Methods: This is an integrative review based on the following guiding question: "What is the perception of postpartum women about the humanized nursing care provided in the pregnancy-puerperal cycle?". The search for articles was carried out in the BDENF, LILACS and SciELO databases, from the controlled descriptors "Humanization of Care", "Obstetric Nursing" and "Nursing Care". Results: The sample totaled 12 articles, which pointed out both positive and negative aspects of humanized nursing care. On the positive aspects, the following were highlighted: in prenatal care, the creation of a bond between professional-patient and as educational actions in health; in the scope of childbirth, professional empathy was emphasized and as good practices recommended by the Cegonha Network and the World Health Organization; in the puerperium context, the nurses' concern with the women's comfort and well-being was revealed. On the negative aspects, one can highlight the execution of procedures without the puerperal woman's prior authorization, reports of coercion and violation of the right to a companion, and non-puerperium to educational health actions aimed at preventing puerperal and/or breast complications. Conclusion: The nurse must be guided by humanization, exercising an idealizing posture of a caregiver character, so that their practice can happen with a view to the realization of women's sexual and reproductive rights before and after the pregnancy-puerperal cycle.
\end{abstract}

Keywords: Nursing; Humanization of Assistance; Obstetric Nursing; Nursing Care.

\footnotetext{
${ }^{1}$ Enfermeira pela Universidade da Integração Internacional da Lusofonia Afro-Brasileira (UNILAB). Pós-graduanda lato sensu em Gestão Hospitalar. Redenção-Ceará, Brasil. Orcid: https://orcid.org/0000-0002-8460-0307

${ }^{2}$ Enfermeiro. Especialista em Enfermagem Cirúrgica. Mestrando em Enfermagem da Universidade da Integração Internacional da Lusofonia AfroBrasileira (UNILAB), Redenção-Ceará, Brasil. Orcid: https://orcid.org/0000-0003-2668-7587

${ }^{3}$ Enfermeira. Especialista em Enfermagem do Trabalho. Mestranda em Enfermagem da Universidade da Integração Internacional da Lusofonia AfroBrasileira (UNILAB), Redenção-Ceará, Brasil. Orcid: https://orcid.org/0000-0001-7716-1388

${ }^{4}$ Enfermeira. Doutora em Enfermagem. Professora do curso de Enfermagem e do Programa de Pós-Graduação em Enfermagem da Universidade da Integração Internacional da Lusofonia Afro-Brasileira (UNILAB), Redenção-Ceará, Brasil. Orcid: https://orcid.org/0000-0002-7331-1673

${ }^{5}$ Enfermeira. Doutora em Enfermagem. Professora do curso de Enfermagem e do Programa de Pós-Graduação em Enfermagem da Universidade da Integração Internacional da Lusofonia Afro-Brasileira (UNILAB), Redenção-Ceará, Brasil. Orcid: https://orcid.org/0000-0002-8626-3527
} 


\section{INTRODUÇÃO}

De acordo com a Política Nacional de Atenção Integral à Saúde da Mulher, o cuidado ao ciclo gravídico-puerperal constitui o arcabouço de serviços destinados ao atendimento da gestante, parturiente, puérpera e recém-nascido ${ }^{(1)}$. Apesar disso, nem sempre se observa esse cuidado na prática. A habilidade das mulheres para atuarem, analisarem e definirem sobre o seu próprio corpo vem sendo deturpada ${ }^{(2)}$.

Em um modelo de atenção humanizada, a mulher é considerada a protagonista de todas as ações relacionadas à sua saúde, em se tratando de uma possibilidade de escolha, por meio do dividir das decisões entre os profissionais da saúde, sendo evidenciado o enfermeiro, e a mulher. Assim, depreende-se que o enfermeiro possui, entre outros, uma missão importante no resgate do direito das mulheres de participarem nas decisões e problemáticas que podem surgir durante o ciclo gravídicopuerperal $^{(3)}$.

A gestação é uma fase bastante significativa na vida da mulher e é preenchida por transformações e valores que se compreendem como únicos, e são experimentados de formas diferenciadas pelas mulheres. É caracterizada por grandes mudanças emocionais e físicas que determinam o acompanhamento pré-natal, sobretudo no acolhimento à mulher, apoio aos sentimentos de medo, dúvidas, angústias, fantasias, a oferta de respostas ou mesmo a ansiedade de saber aquilo que acontecerá com o seu corpo ${ }^{(4)}$.

O Ministério da Saúde recomenda que a gestante deva ser captada o quanto antes, realizar seis consultas, no mínimo, ter acesso a exames laboratoriais, ser acompanhada pela equipe multiprofissional, saber previamente qual o hospital materno em que irá realizar seu parto, entre outras necessidades $^{(1)}$. Ou seja, para que o puerpério seja satisfatório para a mulher, é necessário que desde o pré-natal tenha um acompanhamento contínuo e regular por uma equipe preparada e disposta a ofertar serviços de qualidade.

No âmbito da Estratégia Saúde da Família, o enfermeiro se apresenta como um veículo de educação e um dos profissionais primordiais na assistência à mulher, ao executar ações de saúde na unidade básica, e é por meio dele que ocorre a aproximação com a população na prestação de cuidados em saúde, possibilitando que o processo de aprendizagem torne-se efetivo, sempre embasado no conhecimento científico ${ }^{(5)}$.

Além disso, durante a Consulta de Enfermagem faz-se necessário que o enfermeiro tenha como foco a promoção da saúde maternoinfantil, assim como a assistência humanizada no ciclo gravídicopuerperal e a qualidade da atenção, além de estar atento às mudanças que advêm da gestação, estar atento para as particularidades pertinentes à escolaridade das gestantes e à 
cultura, bem como à possíveis influências religiosas $^{(6)}$.

Estudo realizado em Viçosa-MG apontou que o déficit de conhecimento das puérperas sobre os cuidados no pós-parto está relacionada, principalmente, ao aleitamento materno, no que diz respeito a involução uterina, técnicas corretas de sucção, ingurgitamento mamário, mastite, importância da amamentação, alimentação do pós-parto, entre outras $^{(7)}$, ou seja, todos esses são assuntos de domínio do profissional de Enfermagem e devem ser abordados ainda no âmbito assistencial pelo próprio para a puérpera.

Ouvir as puérperas acerca da assistência humanizada de enfermagem implica em compreender suas interpretações e sentidos sobre este assunto, com foco no saber construído no dia-a-dia dos grupos sociais. As representações dão significado, além de conduzirem e orientarem os grupos sociais. Formam um saber prático tanto por vivenciarem a experiência, que envolve um contexto robusto, quanto por orientarem as comunicações e condutas dos sujeitos, fornecendo um feedback valioso ${ }^{(8)}$.

Tendo em vista a descrição da condição de saúde da puérpera, assim como de que maneira deve ser pautada a assistência de enfermagem, espera-se que esse atendimento tenha adquirido configuração atualizada conforme as políticas de humanização que estão em vigor, haja visto a nova ressignificação da assistência no pré- natal, parto e puerpério. Diante disso, cabe fazer a seguinte questão norteadora: Quais são as percepções das puérperas a respeito da assistência humanizada de enfermagem prestada no ciclo gravídico-puerperal?

O objetivo deste estudo foi analisar na literatura a percepção da puérpera sobre a assistência humanizada de enfermagem dada durante o ciclo gravídico-puerperal.

\section{MÉTODOS}

Trata-se de uma revisão integrativa de literatura, que consiste em uma metodologia de pesquisa capaz de fornecer artifícios para uma melhor utilização das evidências elucidativas sobre determinado assunto aos profissionais. Ademais, também pode promover a incorporação da aplicabilidade de resultados de estudos conclusivos na prática, constituindo num significado ainda mais agregador para a Enfermagem $^{(9)}$.

A revisão integrativa da literatura foi realizada a partir das seguintes etapas: identificação da temática (elaboração da pergunta norteadora estabelecimento de descritores e dos critérios para inclusão/exclusão de artigos); amostragem (seleção dos artigos); categorização dos estudos; definição das informações a serem extraídas dos trabalhos revisados; análise e discussão a respeito das tecnologias utilizadas/desenvolvidas e, por fim, síntese do conhecimento evidenciado nos artigos 
analisados ou apresentação da revisão integrativa ${ }^{(10)}$.

Trata-se de um estudo com coleta de dados realizada a partir de fontes secundárias, por meio do levantamento bibliográfico e com base na seguinte pergunta norteadora: "Qual a percepção de puérperas a respeito da assistência humanizada de enfermagem prestada no ciclo gravídico-puerperal?”

Os critérios de inclusão para a presente revisão foram: artigos originais, divulgados nos idiomas português, espanhol ou inglês, disponíveis gratuitamente e eletronicamente na íntegra, que contemplassem a temática e tendo como público-alvo as puérperas. Foram excluídas as publicações duplicadas e que não responderam à pergunta norteadora.

Utilizou-se os descritores controlados dos Descritores em Ciência da Saúde (DeCS): "Humanização da Assistência", "Enfermagem Obstétrica", "Cuidados de Enfermagem". A busca dos artigos ocorreu no ano de 2020 nas bases de dados BDENF (Base de Dados em Enfermagem), LILACS (Literatura LatinoAmericana e do Caribe em Ciências da Saúde) e SciELO (Scientific Eletronic Library Online), utilizando o operador booleano and para os cruzamentos. Para realização da busca, foi realizado o seguinte cruzamento nas bases de dados LILACS, BDENF e SciELO: Humanização da Assistência and Enfermagem Obstétrica and Assistência de Enfermagem.

Foram encontrados 167 artigos, sendo 143 na base de dados LILACS, 24 na SciELO e nenhum na BDENF. Destes, foram excluídos 148 pelos seguintes motivos: 57 por não responderem à questão norteadora, 61 por não terem como público-alvo as puérperas, 16 por não serem originais e seis por serem publicações duplicadas. Logo, a amostra final deste estudo constituiu-se por 12 artigos (LILACS: 10; SciELO: 02), conforme mostra o fluxograma (Figura 1). 
Figura 1 - Fluxograma de seleção dos trabalhos identificados a partir das bases de dados selecionadas para esta revisão integrativa.

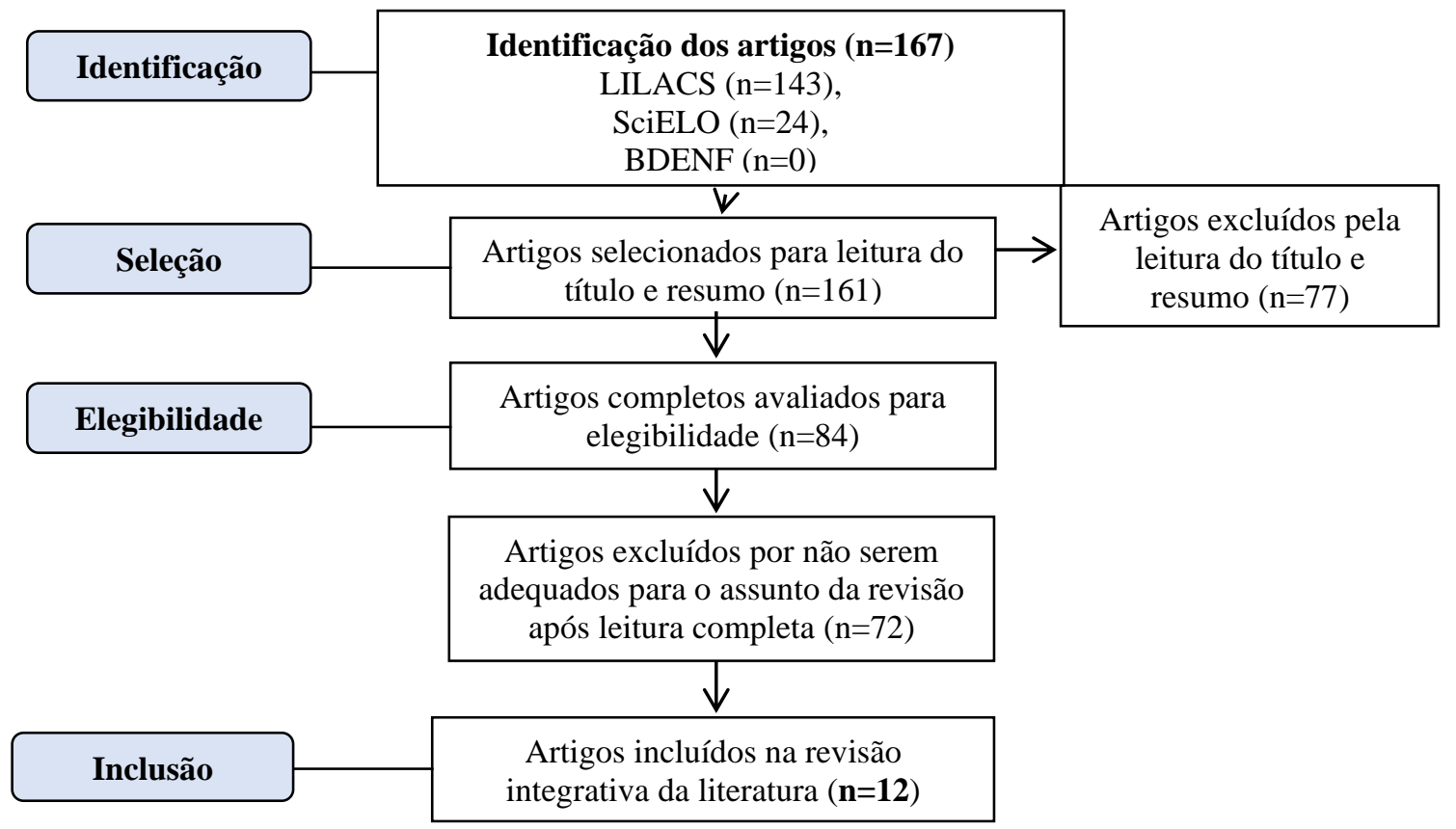

Fonte: Os autores

Para a coleta de dados dos artigos selecionados para compor a amostra, foi utilizado um instrumento validado para captar os principais dados de cada estudo elencado $^{(11)}$. A avaliação das publicações selecionadas foi baseada na classificação proposta por estudiosos que classificam as publicações segundo as forças de evidências $^{(12)}$. A análise de dados evidenciados foi realizada de forma descritiva, sendo apresentada a síntese de cada estudo incluído e comparações entre as pesquisas, explanando diferenças e semelhanças.

\section{RESULTADOS}

A amostra da revisão integrativa foi composta de 12 estudos, sendo prevalente a base de dados LILACS $(10 ; 83,3 \%)$ e as publicações ocorridas no ano de 2017 $(33,3 \%)$. Com relação ao local de origem das publicações, predominaram os estudos realizados no Brasil $(83,3 \%)$, com apenas um estudo realizado na Colômbia $(8,3 \%)$ e outro estudo realizado no México (8,3\%). Destes, apenas um artigo $(8,3 \%)$ foi realizado em instituições privadas, enquanto todos os outros $(11 ; 91,7 \%)$ foram realizados em instituições públicas distribuídas entre centros de parto normal, maternidades públicas e hospitais de ensino.

A maioria das pesquisas $(11 ; 91,6 \%)$ apresentou a abordagem qualitativa, apenas uma utilizou a abordagem quantitativa. Os periódicos utilizados foram predominantemente da área da Enfermagem $(10 ; 83,3 \%)$, sendo o restante de cunho 
interdisciplinar $(1 ; 8,3 \%)$ e da Saúde Maternoinfantil (1;8,3\%).

A Tabela 1 apresenta a síntese dos estudos primários incluídos na revisão integrativa de acordo a base de dados, ano, país, local do estudo, tipo de estudo/evidência, título e objetivo do artigo.

Tabela 1 - Apresentação da síntese dos estudos primários incluídos na revisão integrativa.

\begin{tabular}{|c|c|c|}
\hline $\begin{array}{l}\text { Identificação/Autor/ ano/ } \\
\text { método/ país/ nível de } \\
\text { evidência/ base de dados }\end{array}$ & Título do Estudo & Objetivo do estudo \\
\hline $\begin{array}{c}\mathrm{A}^{(13)} \\
\text { Parada CMGL, Tonete VLP } \\
\text { 2008 } \\
\text { Pesquisa descritiva } \\
\text { qualitativa } \\
\text { Brasil } \\
\text { Nível: } 6 \\
\text { LILACS }\end{array}$ & $\begin{array}{l}\text { O cuidado em saúde } \\
\text { no ciclo gravídico- } \\
\text { puerperal sob a } \\
\text { perspectiva de } \\
\text { usuárias de serviços } \\
\text { públicos }\end{array}$ & $\begin{array}{l}\text { Apreender as representações } \\
\text { sociais de puérperas sobre o } \\
\text { cuidado em saúde no } \\
\text { período pré-natal, no parto e } \\
\text { no puerpério, em um } \\
\text { contexto regional de } \\
\text { serviços públicos de saúde } \\
\text { do interior paulista }\end{array}$ \\
\hline $\begin{array}{c}\mathrm{A}^{(14)} \\
\text { Álvarez-Franco CC } \\
2012 \\
\text { Pesquisa qualitativa de tipo } \\
\text { fenomenológico- } \\
\text { Interpretativo } \\
\text { Colômbia } \\
\text { Nível: } 6 \\
\text { LILACS }\end{array}$ & $\begin{array}{l}\text { Como descrevem o } \\
\text { cuidado de } \\
\text { enfermagem as } \\
\text { mulheres que } \\
\text { apresentaram } \\
\text { hemorragia pós-parto }\end{array}$ & $\begin{array}{l}\text { A abordagem deste tema } \\
\text { surge como produto da } \\
\text { pesquisa sobre o significado } \\
\text { que as mulheres que tiveram } \\
\text { hemorragia pós-parto dão } \\
\text { aos cuidados recebidos pelo } \\
\text { pessoal de enfermagem } \\
\text { durante o trabalho de parto, } \\
\text { parto e pós-parto }\end{array}$ \\
\hline $\begin{array}{c}\mathrm{A}^{(15)} \\
\text { Figueiredo G, Barbieri M, } \\
\text { Gabrielloni MC, Araújo ES, } \\
\text { Henrique AJ } \\
2015 \\
\text { Estudo descritivo e } \\
\text { exploratório de natureza } \\
\text { qualitativa } \\
\text { Brasil } \\
\text { Nível: } 6 \\
\text { LILACS }\end{array}$ & $\begin{array}{l}\text { Episiotomia: } \\
\text { percepções de } \\
\text { puérperas } \\
\text { adolescentes }\end{array}$ & $\begin{array}{l}\text { Identificar a percepção de } \\
\text { puérperas adolescentes com } \\
\text { relação à prática da } \\
\text { episiotomia }\end{array}$ \\
\hline $\begin{array}{c}\mathrm{A} 4^{(16)} \\
\text { Lima PC, Cavalcante MFA, } \\
\text { Melo SSS, et al. } \\
2017 \\
\text { Pesquisa descritiva, } \\
\text { exploratória, de natureza } \\
\text { qualitativa } \\
\text { Brasil } \\
\text { Nível: } 6 \\
\text { LILACS }\end{array}$ & $\begin{array}{c}\text { A vivência de } \\
\text { adolescentes assistidas } \\
\text { por enfermeiros } \\
\text { obstetras durante o } \\
\text { processo de parturição }\end{array}$ & $\begin{array}{l}\text { Descrever a vivência de } \\
\text { adolescentes durante o } \\
\text { processo de parturição e a } \\
\text { atuação da enfermagem } \\
\text { obstétrica com base nos } \\
\text { depoimentos das } \\
\text { adolescentes e discutir à luz } \\
\text { da literatura pertinente }\end{array}$ \\
\hline $\begin{array}{c}\text { A5 } 5^{(17)} \\
\text { Reis C, Ferreira K, Santos D, }\end{array}$ & $\begin{array}{l}\text { Percepção das } \\
\text { mulheres sobre a }\end{array}$ & $\begin{array}{l}\text { Objetivou-se estudar a } \\
\text { percepção das mulheres }\end{array}$ \\
\hline
\end{tabular}




\begin{tabular}{|c|c|c|}
\hline $\begin{array}{c}\text { Tenório I, Brandão WN. } \\
2017 \\
\text { Pesquisa descritiva e } \\
\text { qualitativa } \\
\text { Brasil } \\
\text { Nível: } 6 \\
\text { LILACS }\end{array}$ & $\begin{array}{c}\text { experiência do } \\
\text { primeiro parto: } \\
\text { implicações para o } \\
\text { cuidado de } \\
\text { enfermagem }\end{array}$ & $\begin{array}{l}\text { sobre o primeiro parto no } \\
\text { contexto obstétrico de uma } \\
\text { maternidade do Recife }\end{array}$ \\
\hline $\begin{array}{c}\mathrm{A6}^{(18)} \\
\text { Alvares AS, Corrêa ÁCP, } \\
\text { Nakagawa JTT, Teixeira RC, } \\
\text { Nicolini AB, Medeiros RMK } \\
2018 \\
\text { Estudo de abordagem } \\
\text { quantitativa, descritiva e } \\
\text { transversal } \\
\text { Brasil } \\
\text { Nível: } 6 \\
\text { LILACS }\end{array}$ & $\begin{array}{l}\text { Práticas humanizadas } \\
\text { da enfermeira } \\
\text { obstétrica: } \\
\text { contribuições no bem- } \\
\text { estar materno }\end{array}$ & $\begin{array}{c}\text { Analisar a prática de } \\
\text { enfermeiras obstétricas } \\
\text { atuantes em uma unidade de } \\
\text { pré-parto/parto/pós-parto de } \\
\text { um hospital universitário do } \\
\text { estado de Mato Grosso e o } \\
\text { bem-estar materno } \\
\text { resultante da assistência } \\
\text { nesse cenário }\end{array}$ \\
\hline $\begin{array}{c}\text { A } 7^{(19)} \\
\text { Almeida AF, Brüggemann } \\
\text { OM, Costa R, Junges } \\
2017 \\
\text { Pesquisa qualitativa, } \\
\text { exploratório-descritiva } \\
\text { Brasil } \\
\text { Nível: } 6 \\
\text { LILACS }\end{array}$ & $\begin{array}{l}\text { Separação da mulher e } \\
\text { seu acompanhante no } \\
\text { nascimento por } \\
\text { cesárea: uma violação } \\
\text { de direito }\end{array}$ & $\begin{array}{l}\text { Desvelar a experiência da } \\
\text { mulher e seu acompanhante } \\
\text { que tiveram o direito de } \\
\text { compartilhar o nascimento } \\
\text { de seu filho violado }\end{array}$ \\
\hline $\begin{array}{c}\mathrm{A}^{(20)} \\
\text { Torres DG, Rojas GT, Pareira } \\
\text { PMSD e Peres AM. } \\
2018 \\
\text { Pesquisa descritiva e } \\
\text { qualitativa } \\
\text { México } \\
\text { Nível: } 6 \\
\text { LILACS }\end{array}$ & $\begin{array}{l}\text { Percepção social de } \\
\text { usuários atendidos } \\
\text { exclusivamente por } \\
\text { enfermeiros no estágio } \\
\text { perinatal }\end{array}$ & $\begin{array}{c}\text { Analisar as representações } \\
\text { sociais das usuárias acerca } \\
\text { da atenção prestada pelas } \\
\text { enfermeiras obstetras na } \\
\text { instituição }\end{array}$ \\
\hline $\begin{array}{c}\text { A9 } 9^{(21)} \\
\text { Manzo BF, Costa ACL, Silva } \\
\text { MD, Jardim DMB, Costa LO. } \\
2018 \\
\text { Estudo de caráter descritivo e } \\
\text { abordagem qualitativa } \\
\text { Brasil } \\
\text { Nível: } 6 \\
\text { LILACS }\end{array}$ & $\begin{array}{c}\text { Separação inevitável } \\
\text { do binômio mãe-bebê } \\
\text { no pós-parto imediato } \\
\text { na perspectiva } \\
\text { materna }\end{array}$ & $\begin{array}{c}\text { Compreender o processo de } \\
\text { separação inevitável da mãe } \\
\text { e o bebê no pós-parto } \\
\text { imediato na perspectiva } \\
\text { materna }\end{array}$ \\
\hline $\begin{array}{c}\text { A10 } \\
\text { Queiroz RR, Lima MM, } \\
\text { Gregório VRP, Collaço VS } \\
2019 \\
\text { Pesquisa descritiva, } \\
\text { exploratória, de natureza }\end{array}$ & $\begin{array}{l}\text { Assistência prestada } \\
\text { às mulheres que foram } \\
\text { submetidas à } \\
\text { cesariana por parada } \\
\text { de progressão }\end{array}$ & $\begin{array}{l}\text { Conhecer a percepção das } \\
\text { mulheres submetidas à } \\
\text { cesariana por parada de } \\
\text { progressão do trabalho de } \\
\text { parto sobre a assistência } \\
\text { prestada em um hospital }\end{array}$ \\
\hline
\end{tabular}




\begin{tabular}{|c|c|c|}
\hline $\begin{array}{c}\text { qualitativa } \\
\text { Brasil } \\
\text { Nível: } 6 \\
\text { LILACS }\end{array}$ & & $\begin{array}{l}\text { universitário do sul do } \\
\text { Brasil }\end{array}$ \\
\hline $\begin{array}{c}\text { A11 } \\
\text { Wei CY, Gualda DMR, } \\
\text { Santos Junior HPO. } \\
2011 \\
\text { Pesquisa qualitativa } \\
\text { descritiva } \\
\text { Brasil } \\
\text { Nível: } 6 \\
\text { SCIELO }\end{array}$ & $\begin{array}{l}\text { Movimentação e dieta } \\
\text { durante o trabalho de } \\
\text { parto: a percepção de } \\
\text { um grupo de } \\
\text { puérperas }\end{array}$ & $\begin{array}{l}\text { Conhecer a experiência e a } \\
\text { percepção de um grupo de } \\
\text { mulheres em relação à } \\
\text { deambulação e à dieta } \\
\text { durante o trabalho de parto }\end{array}$ \\
\hline $\begin{array}{c}\text { A12(24) } \\
\text { Silva ALS, Nascimento ER, } \\
\text { Coelho EAC } \\
2015 \\
\text { Pesquisa qualitativa, de } \\
\text { caráter exploratório descritivo } \\
\text { Brasil } \\
\text { Nível: } 6 \\
\text { SCIELO }\end{array}$ & $\begin{array}{c}\text { Práticas de } \\
\text { enfermeiras para } \\
\text { promoção da } \\
\text { dignificação, } \\
\text { participação e } \\
\text { autonomia de } \\
\text { mulheres no parto } \\
\text { normal }\end{array}$ & $\begin{array}{c}\text { Conhecer as práticas de } \\
\text { cuidado utilizadas por } \\
\text { enfermeiras implicadas nos } \\
\text { processos autonomia, } \\
\text { dignificação e participação } \\
\text { de mulheres durante o parto } \\
\text { normal }\end{array}$ \\
\hline
\end{tabular}

Fonte: Os autores (2020)

Após a leitura dos estudos selecionados, percebeu-se que a percepção das puérperas a respeito da assistência humanizada de enfermagem contemplava três momentos do ciclo gravídico-puerperal, a saber: pré-natal, parto e puerpério. A seguir, os resultados encontrados foram organizados em três categorias de acordo com o momento investigado, conforme mostram as Tabelas 2, 3 e 4 .

Tabela 2 - Síntese dos resultados sobre a percepção das puérperas a respeito da assistência humanizada de enfermagem no âmbito do PRÉ-NATAL.

\begin{tabular}{ccc}
\hline Artigo & Aspectos positivos & Aspectos negativos \\
\hline A1 & Assistência caracterizada pela escuta, atenção e & - \\
& cordialidade. \\
& Realização de ações de Educação em Saúde. \\
& Estabelecimento de vínculo profissional-paciente. \\
\hline
\end{tabular}

Fonte: Os autores (2020)

No contexto do pré-natal foi visto que a assistência é pautada no vínculo profissionalpaciente, por meio da escuta e atenção, sendo desenvolvidas ações prioritárias de educação em saúde.

Tabela 3 - Síntese dos resultados sobre a percepção das puérperas a respeito da assistência humanizada de enfermagem no âmbito do PARTO.

\begin{tabular}{ccc}
\hline Artigo & Aspectos Positivos & Aspectos Negativos \\
\hline A1 & Empatia profissional (gestos afetivos, & Relatos verbais de coerção, \\
\hline
\end{tabular}


palavras de encorajamento, estímulos aos métodos não-farmacológicos para o alívio da dor).

\section{falta de acolhimento e insatisfação quanto atendimento dos profissionais.}

\begin{tabular}{|c|c|c|}
\hline A2 & $\begin{array}{l}\text { Empatia profissional (gestos afetivos, } \\
\text { palavras de encorajamento,), sentimento de } \\
\text { segurança e de valor e importância, } \\
\text { percebidos pelas mulheres como algo que } \\
\text { favoreceu a relação mãe-filho, atenção à } \\
\text { saúde maternoinfantil. Realização de } \\
\text { exercícios como protagonistas do } \\
\text { puerpério. } \\
\text { Enfermeiras como canal de comunicação } \\
\text { entre a paciente e a família. }\end{array}$ & - \\
\hline A3 & - & $\begin{array}{l}\text { Atuação profissional precária, } \\
\text { resumida a questionamentos } \\
\text { sem inspeção, manejo } \\
\text { inadequado de lidar com o } \\
\text { momento do término do } \\
\text { trabalho de parto. }\end{array}$ \\
\hline A4 & $\begin{array}{l}\text { Realização de exercícios como } \\
\text { protagonistas do trabalho de parto e } \\
\text { avaliação materno-fetal. Satisfação com } \\
\text { relação à assistência das profissionais. }\end{array}$ & Relatos verbais de coerção. \\
\hline A5 & - & $\begin{array}{l}\text { Relatos verbais de coerção, } \\
\text { não houve suporte continuado } \\
\text { e fragilidade na escuta ativa, } \\
\text { insatisfação quanto aos } \\
\text { profissionais, ausência de } \\
\text { informação/autorização para } \\
\text { realização de procedimentos. }\end{array}$ \\
\hline A6 & $\begin{array}{c}\text { Realização de exercícios como } \\
\text { protagonistas do trabalho de parto, } \\
\text { utilização de boas práticas preconizadas } \\
\text { pela Rede Cegonha e OMS (Organização } \\
\text { Mundial da Saúde). } \\
\text { Profissionais prezando pela fisiologia do } \\
\text { parto, deambulação como estratégia de } \\
\text { evolução do trabalho de parto. } \\
\text { Satisfação com relação à assistência das } \\
\text { profissionais. }\end{array}$ & - \\
\hline A7 & - & $\begin{array}{l}\text { Carência de comunicação } \\
\text { eficaz da equipe com a } \\
\text { parturiente, relatos de } \\
\text { insatisfação quanto ao } \\
\text { atendimento dos } \\
\text { profissionais, ausência de } \\
\text { informação e violação ao } \\
\text { direito assegurado pela Lei do } \\
\text { Acompanhante. }\end{array}$ \\
\hline
\end{tabular}




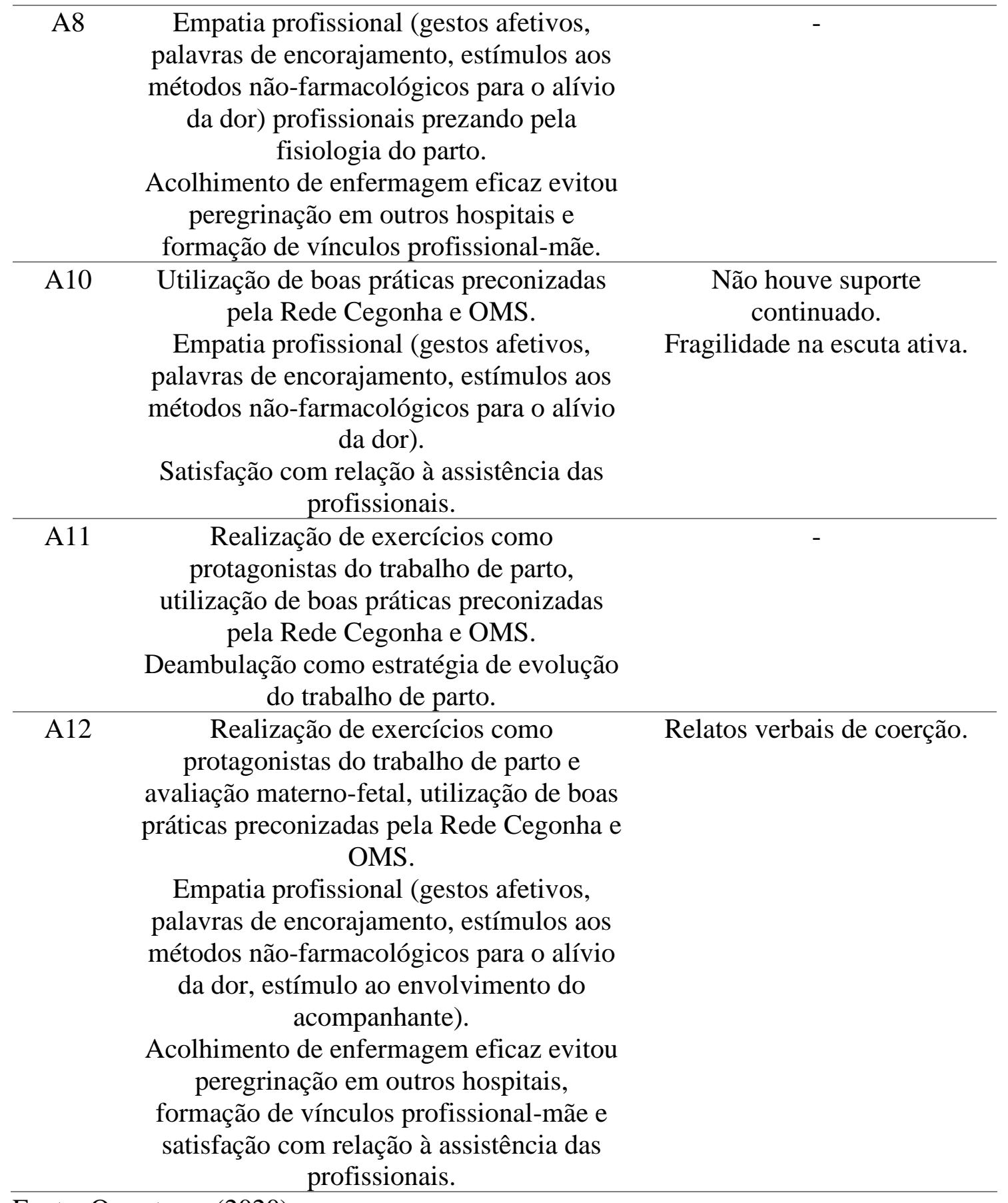

Fonte: Os autores (2020)

$\mathrm{Na}$ assistência humanizada, durante o trabalho de parto e parto, os aspectos positivos mais prevalentes nas pesquisas foram empatia profissional, protagonismo da paciente durante o trabalho de parto e boas práticas preconizadas pela rede cegonha e OMS.
Também foi vista a satisfação em relação a assistência recebida durante o parto, a qual estava vinculada ao cuidado de enfermagem, sendo citado como um ponto positivo, favorecendo a permanência da mesma na instituição diante da peregrinação para parir. 
No entanto, alguns estudos apontaram a insatisfação no atendimento ao parto, sobretudo relacionada ao aspecto de realizar procedimentos sem a autorização da mulher, relatos verbais de coerção e violação ao direito do acompanhante de participar do momento do parto.

Tabela 4 - Síntese dos resultados sobre a percepção das puérperas a respeito da assistência humanizada de enfermagem no âmbito do PUERPÉRIO.

\begin{tabular}{ccc}
\hline Artigo & Aspectos Positivos & Aspectos Negativos \\
\hline A1 & $\begin{array}{c}\text { Impressões positivas do atendimento } \\
\text { prestado pelas enfermeiras. }\end{array}$ & $\begin{array}{c}\text { Ausência de atividades educativas, } \\
\text { sentimento de desrespeito à } \\
\text { necessidade de descanso }\end{array}$ \\
\hline A2 & $\begin{array}{c}\text { Medidas de alívio da dor e promoção } \\
\text { do bem-estar emocional, } \\
\text { comunicação contínua da enfermeira } \\
\text { com a família, assistência de } \\
\text { enfermagem sendo de suma } \\
\text { importância para o apoio do papel } \\
\text { materno, impressões positivas do } \\
\text { atendimento prestado pelas } \\
\text { enfermeiras. }\end{array}$ & - \\
& - & \\
A9 & & Ausência de atividades educativas, \\
& relatos de insatisfação da \\
& & assistência de enfermagem.
\end{tabular}

Fonte: Os autores (2020)

No puerpério as pesquisas evidenciaram que as mulheres apresentam impressões positivas do atendimento prestado pelas enfermeiras, somado a isso, a utilização de métodos farmacológicos e nãofarmacológicos de alívio da dor que a equipe realiza visando proporcionar bem-estar da mulher. Entretanto, como pode-se observar nas tabelas 3 e 4, alguns estudos apontaram insatisfação da assistência de enfermagem durante o período puerperal, sendo citado uma carência de ações educativas para as puérperas lidarem com a nova fase.

\section{DISCUSSÃO}

A base da humanização no âmbito do setor obstétrico está voltada para uma conduta menos intervencionista, mais sensível e respeitando os direitos reprodutivos e sexuais da mulher. A visão abrangida do enfermeiro obstetra juntamente com a implementação de processo de enfermagem é benéfica para que haja uma assistência personalizada para a parturiente, pautada nas evidencias científicas, promovendo o protagonismo da mulher dentro desse processo natural conforme o ritmo do seu próprio corpo ${ }^{(25)}$.

A assistência à mulher no ciclo gravídico-puerperal constitui-se um tradicional pilar da atuação profissional da enfermagem. Pesquisa que compreendeu a 
percepção de puérperas quanto às atividades desenvolvidas na assistência pré-natal evidenciou que a enfermagem foi a profissão mais referenciada quanto ao desenvolvimento das ações de promoção da saúde por meio de atividades educativas $^{(26)}$.

A construção da maternidade que é trabalhada no pré-natal também pode subsidiar a difusão de informações e orientações para amenizar a insegurança e ansiedade, de modo que criar um grupo de preparo para o parto é de suma importância e providencial para sanar dúvidas e compartilhamento de anseios entre as gestantes $^{(27)}$. Algumas condutas podem ser utilizadas por enfermeiros durante a assistência em seus locais de trabalho para desenvolver o preparo da gestante ainda no pré-natal para que cheguem no momento do parto confiantes em sua capacidade natural e fisiológica de parir $^{(28)}$.

$\mathrm{Na}$ assistência ao processo de parturição deve-se levar em consideração não somente as medidas farmacológicas e nãofarmacológicas do alívio da dor do parto, mas todas as ações que são prestadas pela equipe multidisciplinar responsável pela saúde e bem-estar do binômio mãe-filho. Nessa revisão, alguns artigos trouxeram à tona essa reflexão ${ }^{(13-14,20,22,24)}$. Assim, pode-se afirmar que a sensibilização, o comprometimento e a construção de vínculo entre profissionalpaciente são de fundamental consideração para que a prestação do cuidado aconteça de forma a envolver empatia profissional sendo percebida pela paciente para consigo, com seu filho e seus familiares, pois trata-se de um momento em que a mulher encontra-se sensibilizada e frágil ${ }^{(29)}$.

As parturientes consideram a equipe de saúde como as pessoas responsáveis por aliviar a dor e realizar o atendimento de forma que aquele sofrimento dela seja resolvido, ficando vulneráveis e, assim, limitando ou impedindo a expressão de sua autonomia ${ }^{(30)}$. Colocá-las no centro da decisão sobre seu cuidado é um desafio da assistência de saúde na contemporaneidade, sendo essencial que nesse momento se pontue para a paciente que suas visões e desejos serão respeitados, exceto na iminência de riscos substanciais para ela e/ou bebê $\hat{e}^{(31)}$.

Outro ponto que foi destacado em cinco artigos foram os relatos da utilização de exercícios físicos que os enfermeiros lançam mão na hora do $\mathrm{TP}^{(14,16,18,23-24)}$. Essa técnica traz vários benefícios, entre os quais: a própria correção da postura, relaxamento, alongamento e fortalecimento da musculatura. A bola suíça, por exemplo, possibilita que a paciente trabalhe a musculatura do assoalho pélvico - sobretudo levantadores do ânus e pubococcígeo - além da fáscia da pele, o que culmina na ampliação da pelve e colabora para a descida da apresentação fetal até o canal de parto. Ademais, essa conduta tem baixo custo financeiro e é capaz de trazer muitos benefícios psicológicos ${ }^{(32)}$.

Nas últimas décadas algumas ações governamentais têm favorecido a difusão da 
humanização da assistência. Quatro artigos do total de estudos selecionados trouxeram referências sobre a utilização de boas práticas recomendadas pela Rede Cegonha e $\mathrm{OMS}^{(18,22-24)}$. Ao ser criada a Rede Cegonha, em 2011, essa iniciativa propõe a melhoria do atendimento às mulheres durante a gravidez, o parto e o pós-parto e também ao recémnascido e às crianças até dois anos de idade, visando que os profissionais de saúde estejam mais preparados para acolher a gestante e a criança e atendê-la com segurança e o cuidado mais humanizado ${ }^{(33)}$.

Dentre as diretrizes da Rede Cegonha destacam-se a garantia das boas práticas e segurança na atenção ao parto e nascimento, as quais envolvem condutas de uma assistência humanizada, são elas: utilização de métodos não-farmacológicos para aliviar a dor, monitorização fetal, amamentação precoce, oferta de líquidos, ações educativas de saúde, incentivo às posições verticalizadas, movimentar-se durante o TP, contato pele a pele entre mãe e bebê, etc ${ }^{(33)}$.

Além do mais, importa salientar que a atuação do enfermeiro obstetra é estimulada nessa estratégia política ministerial, visto que esses profissionais têm disseminado essas boas práticas. Estudo realizado em Aracaju SE com 373 puérperas evidenciou que esses profissionais transmitem boa vontade $\mathrm{e}$ realizam as ações preconizadas pela Rede Cegonha, como aporte calórico, métodos nãofarmacológicos de alívio da dor, massagem na região sacral, bola suíça, e incentivo à deambulação. Além disso também incentivam o parto vaginal, ressaltando seus benefícios para o binômio mãe-filho, estimulando a amamentação precoce e realizando contato pele a pele entre mãe e filho ${ }^{(34-35)}$.

Apesar da satisfação da assistência de Enfermagem referida pelas puérperas nos estudos analisados, ainda foram encontrados relatados de casos de violência obstétrica, em 5 artigos, fato que vem sobrevindo há décadas, transcendendo em diversos lugares do mundo ${ }^{(13,16-17,19,24)}$. A violência obstétrica é um tema relevante, entretanto, banalizado, uma vez que as parturientes já esperam algum tipo de maus tratos na condução do processo de parturição, levando muito em consideração o histórico da instituição. Logo, as parturientes sujeitam-se à investida de coerção e/ou submissão por temer algum mal contra sua saúde e contra a de seu bebê $\hat{e}^{(36)}$.

Ainda nesse contexto, sobre procedimentos sem a autorização da mulher, um denominador comum às violências obstétricas relatadas é a falta de informação por parte da parturiente e sua família. Essas mulheres precisam sentir-se empoderadas pelo conhecimento e ter atitude para reivindicarem seus direitos, enfatizando para que sejam respeitados. A enfermagem pode dar sua contribuição informando anteriormente sobre a realização dos procedimentos a serem realizados e, dessa forma, promover a autonomia e protagonismo de seus pacientes ${ }^{(37)}$. 
Pesquisa realizada em uma maternidade-escola no interior de São Paulo apontou que um quarto das parturientes foram vitimadas pela violência obstétrica. Atitudes como procedimentos realizados sem autorização das gestantes (episiotomia e amniotomia artificial) ganham destaque entre as expressões desse tipo de violência. $\mathrm{O}$ mesmo estudo revelou que a falta do esclarecimento das dúvidas e a restrição de acompanhante na hora do parto dão margem para o acontecimento desse abuso ${ }^{(38)}$.

Sabendo que o período puerperal compreende uma série de alterações biopsíquicas que influenciam a mulher e seu filho, são esperados sentimentos de incapacidade, ansiedade, receio da imagem corporal e preocupação da criança crescer com saúde. Dessa forma, é fundamental que a equipe de enfermagem desenvolva ações educativas e de assistência a fim de garantir apoio diante das dificuldades inerentes a fase, a fim de caracterizar uma atenção puerperal qualificada $^{(39)}$.

Pesquisa realizada com mães adolescentes, um fato da contemporaneidade, apontou inicialmente um sucesso no aleitamento materno exclusivo, porém a manutenção não se concretizou devido a necessidade de assistência à nutriz de forma mais próxima, holística e humanizada, considerando a singularidade de cada mulher no período puerperal ${ }^{(40)}$. Diante da busca, foi possível perceber a ausência de atividades de educação em saúde nesse sentido, inclusive.
Dessa forma, a orientação torna-se imprescindível desde o início do puerpério imediato para que se reduzam os índices de desmame precoce, potencializem-se os reforçadores positivos da amamentação e minimizem-se os reforçadores negativos, contribuindo, concomitantemente para a evolução desse índice ${ }^{(41)}$.

Há que se falar, ainda, que o puerpério é um período que requer cuidados. Diante disso, é imprescindível que a puérpera tenha conhecimento suficiente sobre isso através de ações educativas qualificadas que consigam ofertar condições a fim de que a mulher consiga cuidar de si e do filho. Essas informações devem ser transmitidas de modo que haja uma escuta ativa das demandas que tiverem as mulheres para que as expectativas sociais a respeito da maternidade não sejam a principal preocupação nesse período. É um momento em que a Enfermagem deve se pautar na prevenção de complicações ${ }^{(42)}$.

Apesar dos relatos de insatisfação na assistência de enfermagem no puerpério em alguns estudos, os aspectos positivos relatados foram muitos, a exemplo da utilização de métodos farmacológicos e nãofarmacológicos de alívio da dor utilizados por esses profissionais. Estudo realizado em uma maternidade pública de Maracanaú-CE com 30 puérperas, evidenciou que o cuidado de enfermagem, apesar de conter influências do modelo biomédico, valorizando a prescrição médica, expressa preocupação com o conforto da puérpera, administrando medicações, 
fornecendo orientações e medidas nãofarmacológicas de alívio da dor. As dores referidas foram: cefaleia, cólicas, dor perineal, traumas mamilares causados pela amamentação e posição inadequada no leito. A fim de sanar o problema, as enfermeiras deram orientações sobre a fisiologia do puerpério, relação da cólica com a amamentação, correção postural, posicionamento e pega adequada na amamentação, prevenção e tratamento da fissura mamilar e ingurgitamento mamário, pautadas na teoria do conforto ${ }^{(43)}$.

Outro ponto que merece destaque, encontrado na análise desta revisão, foi o envolvimento dos familiares durante a assistência de enfermagem puerperal. O envolvimento da família por parte do profissional no cuidado ao binômio mãe-filho é de grande valia, pois o apoio da família durante esse período é fundamental para prevenir a desestabilização da parturiente, o que pode culminar em dificuldades puerperais $^{(44)}$.

Atinente à limitação dessa pesquisa, denota-se uma importante escassez de estudos que abordem a assistência de enfermagem à mulher em todo o ciclo gravídico-puerperal. Outro fator está relacionado ao não esgotamento de todas as bases de dados existentes na literatura. Entretanto, os achados são valiosos para a ciência Enfermagem.

Esse estudo pode agregar em muito às instituições de saúde, aos hospitais de ensino, aos enfermeiros, aos usuários de saúde: às instituições de saúde, por refletirem sobre os índices de qualidade da assistência prestada pelos seus Enfermeiros; aos hospitais de ensino, por poderem exigir essa adequação dos acadêmicos e profissionais que ainda não aderiram às Políticas de Humanização vigentes; aos enfermeiros, devido os resultados apontadas e as recomendações das políticas públicas discutidas; e aos usuários de saúde, por terem acesso ao detalhamento da assistência de Enfermagem que vêm sendo prestada e saberem que têm direito a um atendimento digno, de qualidade, multiprofissional e integrado.

\section{CONSIDERAÇÕES FINAIS}

Percebeu-se que existem aspectos positivos e negativos no contexto da promoção da assistência humanizada de enfermagem durante o ciclo gravídicopuerperal. No que concerne aos fatores positivos no pré-natal foi relatado a importância da criação do vínculo entre profissional-paciente, bem como as ações educativas em saúde; no âmbito do parto foi enfatizado a empatia profissional. No contexto do puerpério as mulheres apontaram a preocupação dos profissionais de enfermagem com o conforto e bem-estar das pacientes, lançando mão de métodos farmacológicos e não-farmacológicos de alívio da dor, acarretando atendimento humanizado e de qualidade nesse período.

Apesar disso, foram relatados pontos negativos no momento do parto, como os 
procedimentos realizados sem autorização prévia, relatos de coerção e violação ao direito de acompanhante, e no puerpério a ausência de ações educativas de saúde com vistas à solução das demandas do momento e à prevenção de intercorrências puerperais e/ou mamárias. Logo, o Enfermeiro que atua nessa área deve estar pautado na humanização, exercendo uma postura idealizadora de caráter cuidador, promovendo uma assistência qualificada durante todo o ciclo gravídicopuerperal. Assim, é necessário que os mesmos desempenhem habilidades técnicas $\mathrm{e}$ conceituais com vista à efetivação dos direitos sexuais e reprodutivos das mulheres.

Por fim, é importante ressaltar que desenvolver mais pesquisas acerca dessa temática, certamente, poderá proporcionar aos pesquisadores enfermeiros uma visão mais panorâmica e minuciosa acerca da assistência obstétrica que vêm sendo prestada no Brasil e nos demais países do mundo. Ademais, poderá auxiliá-lo no reconhecimento e tomada de decisão para as principais necessidades dessas usuárias de saúde. Assim, sugere-se que pesquisas desse cunho possam ser realizadas futuramente.

\section{REFERÊNCIAS}

1. Brasil. Protocolos de Atenção Básica: Saúde das Mulheres. Brasília (DF): Ministério da Saúde. [Internet] 2016 [Acesso em 10 Mai 2020]. Disponível em: https://bvsms.saude.gov.br/bvs/publicacoes/pr otocolos_atencao_basica_saude_mulheres.pdf
2. Rocha NFFD, Ferreira J. A escolha da via de parto e a autonomia das mulheres no Brasil: uma revisão integrativa. Saúde debate. [Internet]. 2020 [Acesso em 10 Mai 2020];44(125):556-68. doi: https://doi.org/10.1590/0103-1104202012521

3. Busanello J, Lunardi Filho WD, Kerber NPDC, Lunardi VL, Santos SSD. Participação da mulher no processo decisório no ciclo gravídico-puerperal: revisão integrativa do cuidado de enfermagem. Rev. Gaúcha Enferm. [Internet]. 2011 [Acesso em 10 Mai 2020];32(4):807-14. doi: https://doi.org/10.1590/S198314472011000400023.

4. Oliveira FVAD. Ações educativas durante a assistência do pré-natal: percepção de gestantes atendidas na Unidade Básica de Barra do Sotero-Croatá/CE, 2018. Trabalho de Conclusão de Curso em Especialista em Saúde da Família. Disponível em: https://ares.unasus.gov.br/acervo/handle/ARE S/20192

5. Andrade LOMD, Barreto ICDHC, Bezerra RC. Atenção primária à saúde e estratégia saúde da família. In: Tratado de saúde coletiva [Internet]. 2006 [Acesso em 10 Mai 2020]:783-835. Disponível em: https://pesquisa.bvsalud.org/portal/resource/pt /his-12715

6. Silva RNA, Mendes PDG, Filha FSSC, Melo Vilanova J, Silva FL. O papel educativo e assistencial de enfermeiros durante o ciclo gravídico-puerperal: a percepção de puérperas. Rev. Interdisc. [Internet]. 2016 [Acesso em 10 Mai 2020];9(3):49-56. Disponível em: https://dialnet.unirioja.es/servlet/articulo?codi go $=6772014$

7. Morais EPAM, Mangueira SO, Perrelli JGA, Rodrigues BHX, Gomes RCM. Avaliação do diagnóstico de enfermagem amamentação ineficaz em puérperas. Rev. Cubana Enfermer. [Internet]. 2020 [Acesso em 10 Mai 2020];36(1):e3112. Disponível em:

http://scielo.sld.cu/scielo.php?script=sci_abstr 
act\&pid=S0864

03192020000100006\&lng=es\&nrm=iso\&tlng $=\mathrm{pt}$

8. Bonet FS, Silva FC, Insfran FFN. A maternidade no comum: relato de experiência em grupos de apoio a puérperas em Porto Alegre. Rev. saude cienc. online. [Internet]. 2020 [Acesso em 10 Mai 2020];9(1):101-16. doi: https://doi.org/10.35572/rsc.v9i1.383

9. Souza MTD, Silva MDD, Carvalho RD. Revisão integrativa: o que é e como fazer. Einstein (São Paulo). [Internet]. 2020 [Acesso em 14 Mai 2020];8:102-6. doi: https://doi.org/10.1590/S1679-

45082010RW1134

10. Pompeo DA, Rossi LA, Galvão CM. Integrative literature review: the initial step in the validation process of nursing diagnoses. Acta paul. enferm. [Internet]. 2009 [Acess in 14 Mai 2020];22(4):434-8. doi: https://doi.org/10.1590/S0103-

21002009000400014

11. Ursi ES, Gavão CM. (2006). Prevenção de lesões de pele no perioperatório: revisão integrativa da literatura. Rev. Latino-Am. Enfermagem. [Internet]. 2006 [Acesso em 15 Mai 2020];14(1):124-31. doi: 10.11606/D.22.2005.tde-18072005-095456

12. Fineout-Overholt E, Melnyk BM, Schultz A. Transforming health care from the inside out: advancing evidence-based practice in the 21st century. Journal of professional nursing. [Internet]; 2005 [Acess in 15 Mai 2020];21(6):335-44.

doi: https://doi.org/10.1590/S0104-

11692006000100017

13. Parada CMGDL, Tonete VLP. Healthcare during the pregnancy-puerperium cycle from the perspective of public service users. Interface (Botucatu). [Internet]. 2008 [Acess in 20 Mai 2020];12(24):35-46. doi: https://doi.org/10.1590/S1414-

32832008000100004

14. Alvarez-Franco CC. Cómo describen el cuidado de enfermeira las mujeres que presentaron hemorragia postparto. Aquichan. [Internet]. 2013 [Acceso en 20 Mai 2020];13(1):17-26. Disponible en: http://www.scielo.org.co/pdf/aqui/v13n1/v13n 1a03.pdf

15. Figueiredo G, Barbieri M, Gabrielloni MC, Araújo ES, Henrique AJ. Episiotomy: perceptions from adolescent puerperae. Invest. Educ. Enferm. [Internet]. 2015 [Acess in 20 Mai 2020];33(2):365-73. doi: https://doi.org/10.17533/udea.iee.v33n2a19

16. Lima PC, Cavalcante MFA, Silva S, Melo S, Feitosa VC, Gouveia MTO. The experience of adolescents assisted by obstetric nurses during parturition. RECOM. [Internet]. 2017 [Acess in 20 Mai 2020];7:e1823. doi: https://doi.org/10.19175/recom.v7i0.1823

17. Reis CC, Souza KRF, Alves DS, Tenório IM, Neto WB. Percepção das mulheres sobre a experiência do primeiro parto: implicações para o cuidado de enfermagem. Cienc. enferm. [Internet]. 2017 [Acess in 20 Mai 2020];23(2):45-56. doi: http://dx.doi.org/10.4067/S071795532017000200045

18. Alvares AS, Corrêa ÁCDP, Nakagawa JTT, Teixeira RC, Nicolini AB, Medeiros RMK. Práticas humanizadas da enfermeira obstétrica: contribuições no bem-estar materno Rev. Bras. Enferm. [Internet]. 2018 [Acesso em 20 Mai 2020];71(6):2620-7. doi: http://dx.doi.org/10.1590/0034-7167-20170290

19. Almeida AF, Brüggemann OM, Costa R, Junges CF. Separação da mulher e seu acompanhante no nascimento por cesárea: uma violação de direito. Cogitare Enferm. [Internet]. 2018 [Acesso em 20 Mai 2020];23(2). https://doi.org/10.1590/S008062342008000200019

20. Torres DG, Rojas GT, Peres AM, Pareira PMSD. Percepción social de usuarias atendidas exclusivamente por enfermeras en la etapa perinatal. Enferm. Actual Costa Rica. 
[Internet]. 2018 [Acesso em 20 Mai 2020];35. doi:

http://dx.doi.org/10.15517/revenf.v0i35.3366 6

21. Manzo BF, Costa ACL, Silva MD, Jardim DMB, Costa LOD. Inevitable mother-baby separation in the immediate postpartum from a maternal perspective. Rev. Bras. Saude Mater. Infant. [Internet]. 2018 [Acess in 20 Mai 2020];18(3):501-07. doi: https://doi.org/10.1590/1806-

93042018000300004

22. Queiroz RR, Lima MM, Gregório VRP, Collaço VS. Assistência prestada às mulheres que foram submetidas à cesariana por parada de progressão. Rev. Min. Enferm. [Internet] 2019 [Acesso em 20 Mai 2020];23:e-1204. doi: 10.5935/1415-2762.20190052

23. Wei CY, Gualda DMR, Junior HPOS. Walking and diet during labor: perceptions from a group of postpartum women. Texto contexto enferm. [Internet]. 2011 [Acess in 20 Mai 2020];20(4):717-25. doi: http://dx.doi.org/10.1590/S010407072011000400010

24. Silva ALS, Nascimento ER, Coelho EAC. Nurses practices to promote dignity, participation and empowerment of women in natural childbirth. Esc. Anna Nery. [Internet]. 2015 [Acess in 20 Mai 2020];19(3):424-31. doi: $\quad$ http://dx.doi.org/10.5935/14148145.20150056

25. Santos RB, Ramos KS. Systematization of nursing care in the Obstetrical Center Rev. Bras. Enferm. [Internet]. 2012 [Acess in 20 Mai 2020];65(1):13-8. doi: https://doi.org/10.1590/S003471672012000100002

26. Maeda TC, Parreira BDM, Silva SR, Oliveira ACAO. Importância atribuída por puérperas às atividades desenvolvidas no prénatal. Rev. Enferm. Atenção Saude. [Internet]. jul/dez 2014 [Acesso em 01 Jun 2020];3(2):618. doi: https://doi.org/10.18554/
27. Basso JF, Monticelli M. Las expectativas de participación de mujeres embarazadas y sus acompañantes para realizar un parto humanizado. Rev. Latino-Am Enfermagem. [Internet]. 2010 [Acesso em 01 Jun 2020];18(3):99-107. Disponível em: https://www.scielo.br/j/rlae/a/jYHPcRTxS4P SR7JwB55Tp4g/?format=pdf\&lang=es

28. Riesco MLG, Oliveira SMJV. Enfermagem baseada em evidências científicas: um enfoque assistencial. Associação Brasileira de Enfermagem; Associação Brasileira de Obstetrizes e Enfermeiras Obstétricas. PROENF: saúde materna e neonatal. Porto Alegre: Artmed. 2010.

29. Escobal APL, Soares MC, Meincke SMK, Costa Kerber NP, dos Santos CP, Carvalho GP. Experiências das Puérperas Adolescentes no Processo de Parturição. Rev. Fund. Care. Online. [Internet]. 2016 [Acesso em 03 Jun 2020];8(3):4711-16. Disponível em: https://dialnet.unirioja.es/servlet/articulo?codi go $=5618272$

30. Griboski RA, Guilhem D. Mulheres e profissionais de saúde: o imaginário cultural na humanização ao parto e nascimento. Texto Contexto Enferm. [Internet]. 2006 [Acesso em 03 Jun 2020];15(1):107-14. doi: http://dx.doi.org/10.1590/s010407072006000100013

31. Brasil Ministério da Saúde. Cadernos Humaniza SUS: Volume 1. Formação e intervenção. Brasília: Ministério da Saúde; 2010. 250 p. (Série B. Textos Básicos de Saúde). Disponível em: https://bvsms.saude.gov.br/bvs/publicacoes/ca dernos_humanizaSUS.pdf

32. Silva LM, Oliveira SMJV, Silva FMB, Alvarenga MB. Using the Swiss ball in labor. Acta paul. enferm. [Internet]. 2011 [Acesso in 3 Jun 2020];24(5):656-62. doi: https://doi.org/10.1590/S010321002011000500010

33. Brasil. Ministério da Saúde. Portaria n.1.459, de 24 de junho de 2011. Institui, no 
âmbito do Sistema Único de Saúde - SUS - a Rede Cegonha. Brasília: Diário Oficial da União; 2011. Disponível em: https://bvsms.saude.gov.br/bvs/saudelegis/gm /2011/prt1459_24_06_2011.html

34. Brasil. Ministério da Saúde. Portaria n. ${ }^{\circ}$ 11, de 07 de janeiro de 2015. Brasília: Diário Oficial da União; 2015. Disponível em: https://bvsms.saude.gov.br/bvs/saudelegis/gm /2017/MatrizesConsolidacao/comum/15490.ht $\mathrm{ml}$

35. Cardoso JE, Barbosa RHS. O desencontro entre desejo e realidade: a "indústria" da cesariana entre mulheres de camadas médias no Rio de Janeiro. Rev. Saude Colet. [Internet]. 2012 [Acesso em 05 Jun 2020];22(1):35-52. Disponível em https://www.scielosp.org/article/physis/2012. v22n1/35-52/

36. Zanardo GLDP, Uribe MC, Nadal AHRD, Habigzang LF. Obstetrical Violence in Brazil: A narrative review. Psicol. Soc. [Internet]. 2017 [Acess in 05 Jun 2020];29:e155043. doi: https://doi.org/10.1590/1807-

0310/2017v29155043

37. Alvarenga SP, Kalil JH. Violência obstétrica: como o mito "parirás com dor" afeta a mulher brasileira. Rev. da Univ. Val. do Rio Verd. [Internet]. 2016 [Acesso em 05 Jun 2020];14(2):641-9. doi: http://dx.doi.org/10.5892/ruvrd.v14i2.2755

38. Biscegli TS, Grio JM, Melles LC, Ribeiro SRMI, Gonsaga RAT. Violência obstétrica: perfil assistencial de uma maternidade escola do interior do estado de São Paulo. CuidArte Enferm. [Internet]. 2015 [Acesso em 05 Jun 2020];9(1):18-25. Disponível em: https://pesquisa.bvsalud.org/portal/resource/pt /bde-26951

39. Garcia ESGF, Leite EPRC, Nogueira DA. Assistência de Enfermagem às Puérperas em Unidades de Atenção Primária. Rev. Enferm. UFPE on line. [Internet]. 2013 [Acesso em 05 Jun 2020];7(10):5923-8. Disponível em: https://www.unifal-mg.edu.br/extensao/wpcontent/uploads/sites/96/2019/07/ASSIST_N
CIA-DE-ENFERMAGEM-_S-PU_RPERASEM-UNIDADES-DE-ATEN_OPRIM_RIA.pdf

40. Clapis CV, Fabbro MRC, Beretta MIR. The practice of breastfeeding of teen mothers in the first six months of life of the child. Cienc Cuid Saude. [Internet] 2013 [Acess in 07 Jun 2020];12(4):104-10. doi: https://doi.org/10.4025/cienccuidsaude.v12i4. 20911

41. Urbanetto PDG, Costa AR, Gomes GC, Nobre CMG, Xavier DM, Jung BC. Facilities and difficulties found by mothers to breastfeed Rev. Fund. Care Online. [Internet] 2018 [Acess in 07 Jun 2020];10(2):399-405. doi: $\quad$ https://doi.org/10.9789/21755361.2018.v10i2.399-405

42. Almeida MS, Silva IA. Women's needs in immediate puerperium in a public maternity in Salvador, Bahia, Brazil. Rev. esc. enferm. USP. [Internet]. 2008 [Acess in 07 Jun 2020];42(2):347-54. doi: https://doi.org/10.1590/S008062342008000200019

43. Figueiredo J. V., Fialho A. V. M., Mendonça G. M. M., Rodrigues D. P, Silva L. F. A dor no puerpério imediato: contribuição do cuidado de enfermagem. Rev. Bras. Enferm. [Internet]. 2018 [Acesso em 07 Jun 2020];71(Suppl 3):1343-50. doi: http://dx.doi.org./10.590/0034-7167-20170345

44. Porto AAS, Costa LP, Velloso NA. Humanização da assistência ao parto natural: uma revisão integrativa. Rev. Ciencia Tecnologia. [Internet]. 2015 [Acesso em 07 Jun 2020];1(1):12-19. doi: tp://dx.doi.org/10.33053/cientec.v1i1.284

\section{Autor correspondente}

José Erivelton de Souza Maciel Ferreira. Rua Antônia Vicente, Baturité-CE 62.760-000, +5585998116578, eriveltonsmf@gmail.com.

Submissão: 2021-08-28

Aprovado: 2021-10-11 